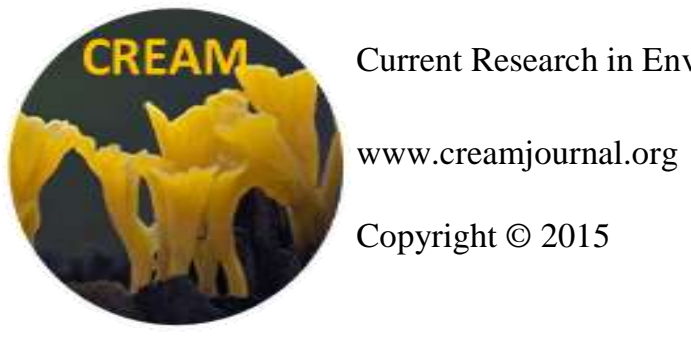

\title{
Psathyrella (Psathyrellaceae, Agaricales) species collected on dung from Punjab, India
}

\author{
Amandeep $\mathrm{K}^{1^{*}}$, Atri $\mathrm{NS}^{2}$ and Munruchi $\mathrm{K}^{2}$ \\ ${ }^{1}$ Desh Bhagat College of Education, Bardwal-Dhuri-148024, Punjab, India. \\ ${ }^{2}$ Department of Botany, Punjabi University, Patiala-147002, Punjab, India.
}

Amandeep K, Atri NS, Munruchi K 2015 - Psathyrella (Psathyrellaceae, Agaricales) species collected on dung from Punjab, India. Current Research in Environmental \& Applied Mycology 5(2), 128-137, Doi 10.5943/cream/5/2/6

\begin{abstract}
This paper gives an account of five Psathyrella species from Punjab state in India along with key for their identification. The collections of the identified taxa were obtained from a variety of coprophilous habitats having different herbivorous dung types. These belong to Psathyrella kauffmanii var. kauffmanii, P. vanhermanii, P. fimicola, $P$. sphaerocystis and P. flocculosa. For all the taxa, dung types on which they were found growing are mentioned. Psathyrella kauffmanii var. kauffmanii, $P$. vanhermanii, $P$. sphaerocystis and $P$. flocculosa are new fungus records for India. The taxonomy of all these 04 new records is discussed along with the drawings of morphological and anatomical features and their distinctive characters are described and compared with similar taxa.
\end{abstract}

Key words - Basidiomycota - diversity - dung - spore bleaching - systematics - taxonomy

\section{Introduction}

The genus Psathyrella (Fr.) Quél., belonging to the family Psathyrellaceae Readhead, Vilgalys \& Hopple, is characterized by grayish, pale clay to deep brown, thin, fragile, hygrophanous pileus having non-deliquescent lamellae, smooth truncated basidiospores which loose color in concentrated Sulphuric Acid and distinct cellular to hymeniform pileus cuticle. The species are saprotrophic in habitat and most of the species occur on soil or on wood. A number of Psathyrella species are coprophilous and grow on dung of various animals (Singer 1986, Pegler 1986, Amandeep et al. 2013).

Kirk et al. (2008) recognized 400 species under this genus. MycoBank (www.mycobank.org) documents 834 records of the genus till December 2014. Larsson and Örstadius (2008) reported fourteen coprophilous species of Psathyrella in the Nordic countries. Most species of this genus are worldly distributed and 49 species have already been recorded from India prior to the present study (Saini \& Atri 1995, Natarajan et al. 2005, Kaur et al. 2011, 2013, Mohanan 2011, Amandeep et al. 2013, Pushpa \& Purushothama, 2013). From Punjab state, 13 species namely P. candolleana (Fr.) Maire, P. empyreumatica (Berk. \& Broome) Sacc., P. fimicola Atri et al., P. floccosa (Earle) A. H. Sm., P. incerta (Peck) A. H. Sm., P. longistriata (Murrill) Smith, P. moshiana Pegler, P. naivashaiensis Pegler, Psathyrella naivashaiensis var. macrospora Kaur et al., P. obtusata (Fr.) Smith, P. pseudocandolleana Smith, P. singeri A. H. Sm., and P. 
spintrigera (Fr.) Konrad \& Maubl. are known so far (Sarwal \& Rawla 1983, Saini \& Atri 1993, Kaur et al. 2011, 2013, Amandeep et al. 2013). Presently the diversity of coprophilous species of Psathyrella has been studied and 05 species identified as Psathyrella kauffmanii var. kauffmanii, $P$. vanhermanii, $P$. fimicola, $P$. sphaerocystis and $P$. flocculosa were collected growing on different types of herbivorous dung.

\section{Material \& Methods}

The standard methodology and terminology as described by Singer (1986), Pegler (1977, 1986) and Atri et al. (2005) was used for collecting and describing the agarics. The colour terminology used for macroscopic description is that of Kornerup \& Wanscher (1978). The specimens were preserved according to the techniques given by Smith (1949) and Atri \& Saini (2000). The drawings of microscopic details were made with the aid of camera lucida under an oil immersion lens. All the collections examined have been deposited in the Herbarium of Botany Department, Punjabi University, Patiala (Punjab), India under PUN.

Key to the investigated coprophilous species of Psathyrella

1 Annulus present

1'Annulus absent. 4

$2 \quad$ Stipe $\quad 0.2-0.3 \quad$ cm $\quad$ broad, $\quad$ hollow; $\quad$ pleurocystidia present...................................................... kauffmanii var. kauffmanii

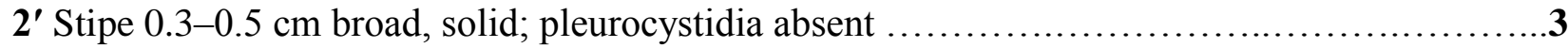
3 Pileus conical to applanate, umbonate; cuticle fully peeling; caulocystidia absent...................................................................... vanhermanii 3' Pileus broadly convex to semiglobate, ex-umbonate; cuticle not peeling; caulocystidia present P. fimicola 4 Carpophores $7-8.5 \mathrm{~cm}$ in height; pleurocystidia present; lamellae adnate; pileal veil powdery granulose. P. sphaerocystis 4' Carpophores 2.2-3.2 cm in height; pleurocystidia absent; lamellae adnexed; pileal veil appressed floccose P. flocculosa

\section{Taxonomic descriptions}

Psathyrella kauffmanii var. kauffmanii Smith in Mem. N. Y. Bot. Gdn. 24: 69, 1972. Figs. $1-2$ Carpophores $2.8-7.8 \mathrm{~cm}$ in height. Pileus $1.2-2.2 \mathrm{~cm}$ broad, $1-1.4 \mathrm{~cm}$ high, conical to campanulate; umbonate, umbo short, reddish brown $\left(8 \mathrm{D}_{4}\right)$; surface dry, pale yellow $\left(2 \mathrm{~A}_{3}\right)$, hygrophanous, fading to buff color; pileal veil powdery and fibrillose, fibrils arranged in concentric rings, covering the entire pileus surface, white; margin irregular, splitting at maturity, slightly striate, with white appendiculate veil; cuticle fully peeling; flesh thin, up to $0.2 \mathrm{~cm}$ thick, fragile, white, unchanging; taste bitter; odor mild. Lamellae adnexed to adnate, equal, crowded, narrow, up to $0.2 \mathrm{~cm}$ broad, white when young, grayish brown $\left(6 \mathrm{D}_{3}\right)$ at maturity, fragile; gill edges smooth. Spore print grayish brown $\left(6 \mathrm{D}_{3}\right)$. Stipe central, $2.5-7.6 \mathrm{~cm}$ long, $0.2-0.3 \mathrm{~cm}$ broad, cylindrical, obclavate, striated, hollow, pruinose, surface white, unchanging, white mycelium present around the base; annulate, annulus single, membranous, superior, peronate, attached.

Basidiospores $6.8-9.3 \times 4.3-6 \mu \mathrm{m}(\mathrm{Q}=1.56)$, ovoid to ellipsoidal, with a narrow inconspicuous germ pore, thick-walled, smooth, yellowish brown with dark brown walls, bleaching in concentrated $\mathrm{H}_{2} \mathrm{SO}_{4} ; 2-, 3-$, 4-guttulate, mostly 2-guttulate, guttules bluish. Basidia 15.3-19.5 $\times$ 6.8-9.3 $\mu \mathrm{m}$, clavate, 2- and 4-spored, mostly 4-spored, thin-walled, hyaline; sterigmata 3.4-4.3 $\mu \mathrm{m}$ long. Gill edges sterile. Cheilocystidia $17-29 \times 6.8-13.6 \mu \mathrm{m}$, polymorphic, lageniform, clavate to ventricose fusoid, thin-walled, hyaline, some with apical encrustations. Pleurocystidia in fascicles of 2-, 3-, 4- to scattered, $25.5-46 \times 10-15.3 \mu \mathrm{m}$, polymorphic, cylindrical, clavate to ventricose fusoid, with round apex, thin-walled, granular. Pileus cuticle 2- to 3- layered deep cellular epithelium, 58-63 $\mu \mathrm{m}$ thick; cellular elements 20.4-49.3 $\times 13.6-18.7 \mu \mathrm{m}$, 


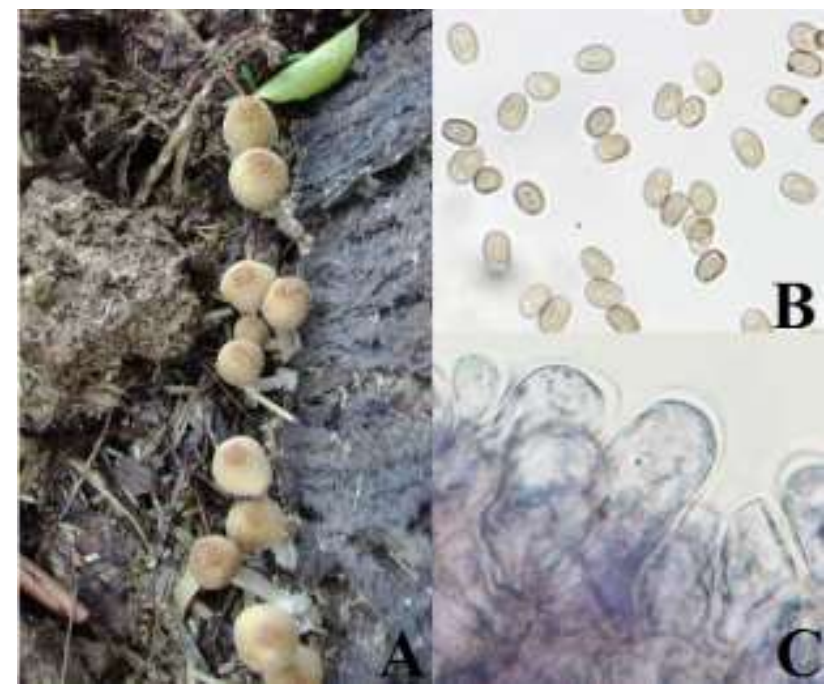

Fig. 1 - Psathyrella kauffmanii var. kauffmanii. A Carpophores growing in natural habitat. B Basidiospores. C Pileus cuticle elements.

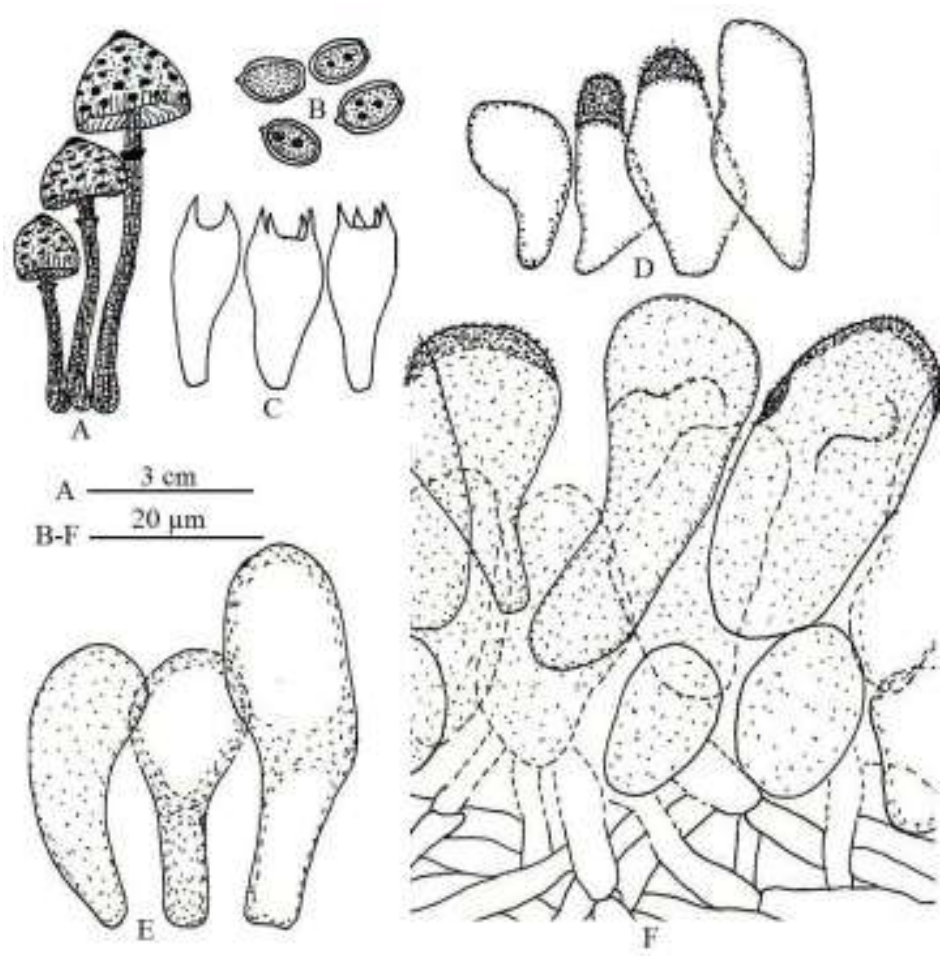

Fig. 2 - Psathyrella kauffmanii var. kauffmanii. A Carpophores. B Basidiospores. C Basidia. D Cheilocystidia. E Pleurocystidia. F Pileal elements. G Caulocystidia.

polymorphic, vesiculose, subglobose, piriform, clavate to sphaeropedunculate, thin-walled, granular, some densely encrusted at the apices; pileus context homoiomerous, made up of intermingled narrow thin-walled hyaline 3.4-10 $\mu \mathrm{m}$ broad hyphae. Hymenophoral trama composed of parallel, narrow, thin-walled 3.4-6.8 $\mu \mathrm{m}$ broad hyphae. Subhymenium pseudoparenchymatous. Stipe cuticle with scattered caulocystidia; stipe context made up of parallel narrow thin-walled hyaline $3.4-10 \mu \mathrm{m}$ broad hyphae. Caulocystidia $18.7-27 \times 6.8-10 \mu \mathrm{m}$, clavate to cylindrical, thinwalled, hyaline. Clamp connections present in pileus and stipe context hyphae.

Material examined - India, Punjab, Moga, Loahgarh, alt. 217 m, growing in caespitose clusters on buffalo dung heap under Azadirachta indica tree, 28 July 2009, Amandeep Kaur, PUN 4318. 
Discussion - The details of this specimen agree well with those given for P. kauffmanii var. kauffmanii by Smith (1972) who reported the type species growing gregariously to scattered under beech-maple stands from North America. This species belongs to subgenus and section Pseudostropharia Smith because of the presence of annulate stipe. Psathyrella kauffmanii var. exannulata is close to it except for the absence of annulus on the stipe and having shorter capitate pleurocystidia. Smith (1972) reported its habit on humus, however, presently it has been documented growing in caespitose manner on the buffalo dung heap. It is a new fungus record from India.

Psathyrella vanhermanii Smith in Mem. N. Y. Bot. Gdn. 24: 79, 1972.

Fig. 3

Carpophores $3.2-9 \mathrm{~cm}$ in height. Pileus $1.4-4 \mathrm{~cm}$ broad, $1.3-1.5 \mathrm{~cm}$ high, conical to applanate; umbonate, umbo broad, brown; surface moist, yellowish white $\left(2 \mathrm{~A}_{2}\right)$, hygrophanous, changing to yellowish brown $\left(5 \mathrm{E}_{5}\right)$ when dried; pileal veil scaly, scales white, floccose, appressed fibrillose, covering the entire pileus surface, removable on touching; margin irregular, reflexed at maturity; cuticle fully peeling; flesh membranous, yellowish white, unchanging; taste and odor mild. Lamellae adnate, unequal, 3-sized, subdistant, moderately broad, up to $0.4 \mathrm{~cm}$ broad, cream when young, dark brown $\left(6 \mathrm{~F}_{5}\right)$ at maturity; gill edges wavy. Stipe central, 3-8.5 cm long, 0.3-0.5 $\mathrm{cm}$ broad, cylindrical, equal in diameter throughout, solid, white, unchanging, pruinose-fibrillose from veil remnants below the annulus, with white mycelium at the base; annulate, annulus single, white, ring like, movable.

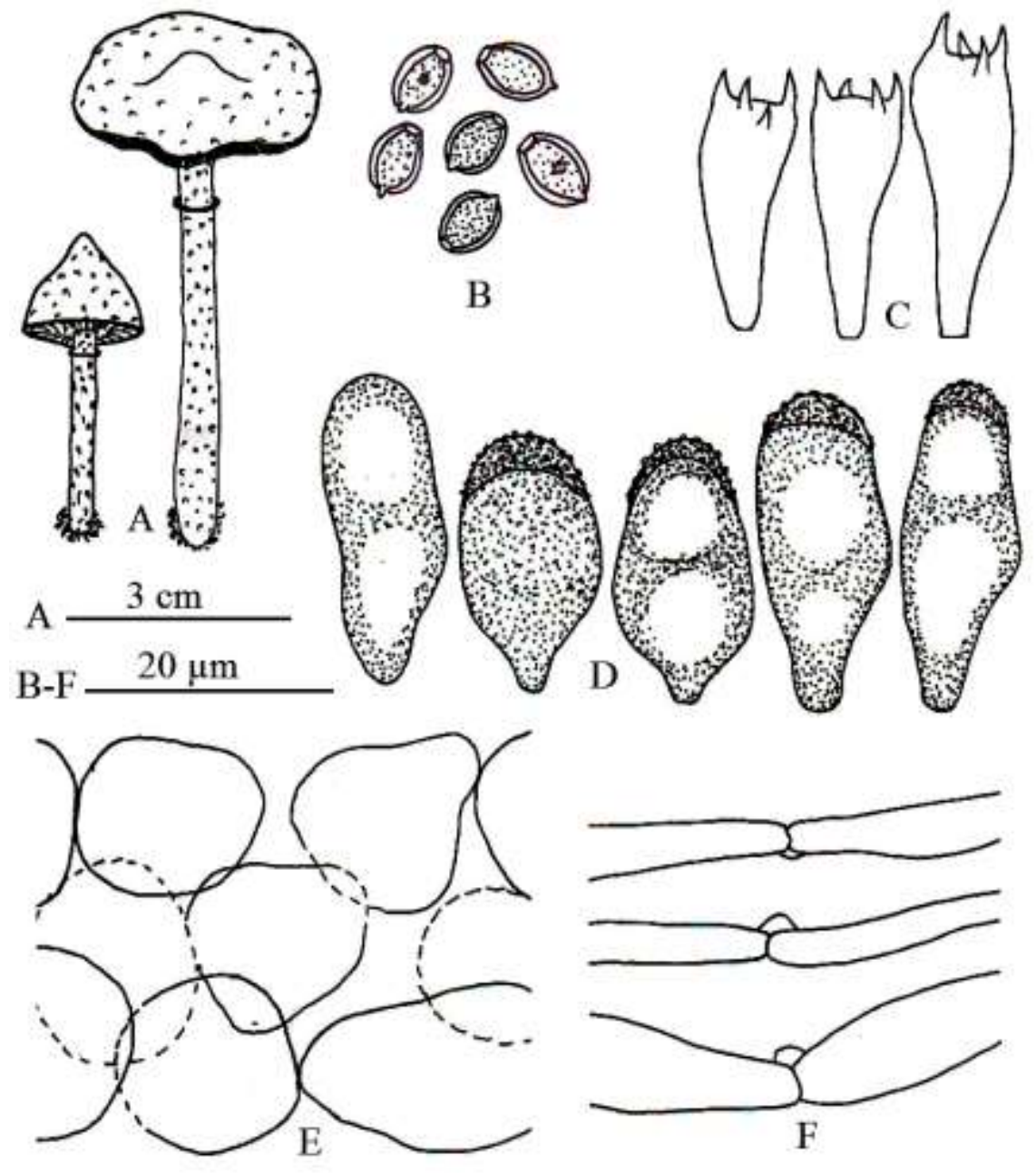

Fig. 3 - Psathyrella vanhermanii. A Carpophores. B Basidiospores. C Basidia. D Cheilocystidia. E Pileal cuticle elements. F Clamp connections in pileus context hyphae. 
Basidiospores 5-7.6 $\times 3.4-5 \mu \mathrm{m}(\mathrm{Q}=1.5)$, ellipsoidal, with a truncate germ pore, thick walled, smooth, brown, loose color in concentrated $\mathrm{H}_{2} \mathrm{SO}_{4}$. Basidia 17-27.2 $\times 5.7-8.5 \mu \mathrm{m}$, clavate, 4-spored, thin-walled, hyaline; sterigmata 2.5-4.3 $\mu \mathrm{m}$ long. Brachycystidia present between the basidia. Gill edges heteromerous. Cheilocystidia 13-27.2 $\times 7-12 \mu \mathrm{m}$, cylindrico-clavate to pedicellate clavate, thin-walled, granular, densely granular at tips. Pleurocystidia absent. Pileus cuticle 2-3 layered deep cellular epithelium, cells 10-22 $\mu \mathrm{m}$ broad, subglobose, thin walled, hyaline; pileus context homoiomerous, made up of interwoven thin-walled hyaline $2.8-12 \mu \mathrm{m}$ broad hyphae. Hymenophoral trama hyphae parallel thin-walled 5-15.3 $\mu \mathrm{m}$ broad. Subhymenium pseudoparenchymatous. Stipe context hyphae intermingled, septate, thin-walled, hyaline 4.3-21.3 $\mu \mathrm{m}$ broad. Clamp connections present in pileus and stipe context hyphae.

Material examined - India, Punjab, Mohali, Parol, alt. $316 \mathrm{~m}$, growing in groups on buffalo dung, Amandeep Kaur, 14 July 2007, PUN 4316; Ludhiana, Issru, alt. 254 m, growing in groups on buffalo dung, 17 June 2008, Amandeep Kaur, PUN 4315.

Discussion - The above collections possess annulate stipe and there are no pleurocystidia on the sides of the lamellae. These are the typical features of subgenus Pseudostropharia Smith and section Spintrigerae (Fr.) Sing. The diagnostic characters of above examined collections fall in the overall taxonomic circumscription of $P$. vanhermanii as given by Smith (1972). This species is close to $P$. candolleana and $P$. incerta. The former species can be distinguished on the basis of honey brown pileus when young and spore size range which is 6.5-9.5 × 4-5 $\mu \mathrm{m}$ (Kuo 2011a) and the later species has pale yellow pileus, purplish gray to purplish brown gills and spores measuring 6-7.5 × 3.5-4 $\mu \mathrm{m}$ (Kaur et al. 2011, Kuo 2011b). Psathyrella vanhermanii is a new fungus record from India. Presently both the above examined collections have been made from buffalo dung heaps.

Psathyrella fimicola NS Atri, Munruchi Kaur and Amandeep Kaur in J. New Biol. Reports 2(3): 276, 2013.

Fig. 4

Material examined - India, Punjab, Patiala, Harigarh, alt. 251m, growing in a group on horse dung, 18 June 2011, Amandeep Kaur, PUN 4317.

Discussion - This species belongs to subgenus and section Candolleana Smith (Smith, 1972) because of its appendiculate pileal margin, absence of pleurocystidia and basidiospores within the range of 5-10 $\mu \mathrm{m}$ long. It is characterized by medium-sized carpophores $(5.5-6.7 \mathrm{~cm}$ in height), brownish yellow pileus surface, prominent floccose-powdery veil remnants, non-striate appendiculate pileal margin and white stipe which bruise brown. It has small spores $(5.7-8 \times 3.4-5$ $\mu \mathrm{m}$ in size) which turn into light grayish brown to grayish hyaline in $\mathrm{KOH}$ and the hyphae of subcuticular region of pileus appear grayish hyaline in $\mathrm{KOH}$ under the microscope. Psathyrella luteopallida of section Candolleana and P. subhyalinispora of section Subatratae (Romagnesi) Singer are the two species which are quite close to this species. Psathyrella luteopallida differs from it in having smaller carpophores (up to $2.5 \mathrm{~cm}$ long), pale yellow to mouse gray pileus surface, larger spores $(9-12 \times 5-6 \mu \mathrm{m})$ which lack germ pore and in the absence of caulocystidia. Psathyrella subhyalinispora is different from $P$. fimicola in having larger spores $(7-9 \times 4.5-6 \mu \mathrm{m})$, dingy yellow-brown glabrous pileus, exannulate stipe and lacking caulocystidia (Smith, 1972). Amandeep et al. (2013) reported the type species from Punjab.

Psathyrella sphaerocystis Orton in Notes Roy. Bot. Gard. Edinburgh 26: 57. $1964 . \quad$ Figs. $5-6$ Carpophores $7-8.5 \mathrm{~cm}$ in height. Pileus $2-3 \mathrm{~cm}$ broad, $2.5-3 \mathrm{~cm}$ high, conical to campanulate; surface dry, creamish brown, hygrophanous, fading to light brown; pileal veil white powdery granulose when young, smooth at maturity; margin irregular, slightly incurved, splitting, translucent striate, grayish black; cuticle fully peeling; flesh thin, fragile; taste and odor not distinctive. Lamellae adnate, equal, crowded, moderately broad, up to $0.25 \mathrm{~cm}$ broad, white when young, grayish brown at maturity, fragile; gill edges smooth. Stipe $6.8-8.2 \mathrm{long}, 0.5-0.9 \mathrm{~cm}$ broad, cylindrical, tapering upwards, with slightly bulbous base, hollow, surface white, extensively fibrillose throughout the stipe surface, fragile; annulus absent. 


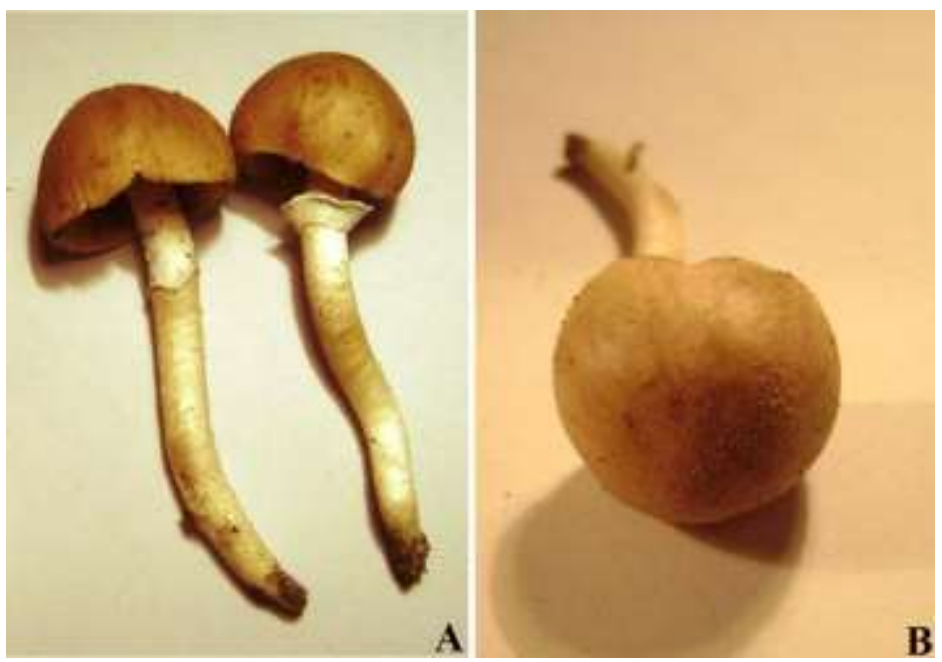

Fig. 4 - Psathyrella fimicola. A Carpophores. B Pileus surface.

Basidiospores 7-10 (11) $\times 5-7(7.7) \mu \mathrm{m}(\mathrm{Q}=1.4)$, ovoid to ellipsoidal, with a truncate germ pore, thick-walled, smooth, reddish brown in $\mathrm{KOH}$, reddish yellow in Melzer's reagent, bleaching in concentrated $\mathrm{H}_{2} \mathrm{SO}_{4}$. Basidia 12.8-17 $\times 6.4-8.4 \mu \mathrm{m}$, clavate, 4-spored, thin-walled, hyaline to granular along the walls; sterigmata 2.8-3.6 $\mu \mathrm{m}$ long. Gill edges sterile. Cheilocystidia 15.5-28.5 $\times$ 8.5-10 $\mu \mathrm{m}$, cylindrical to clavate, thin-walled, hyaline. Pleurocystidia scattered, 18.5-22.7 x 7$11.4 \mu \mathrm{m}$, clavate-pedicellate, with round apex, thin-walled, hyaline. Pileus cuticle 3-4 layered cellular epithelium, cells $28.4-50 \times 24-33 \mu \mathrm{m}$, vesiculose, subglobose, clavate to piriform, reddish brown in $\mathrm{KOH}$; velar remnants in the form of sphaerocysts, cells $29-46 \mu \mathrm{m}$ broad, thin-walled, with granular depositions along the walls; pileus context homoiomerous, made up of $4.3-8.5 \mu \mathrm{m}$ broad hyphae. Hymenophoral trama regular, composed of thin-walled 2.8-8.5 $\mu \mathrm{m}$ broad hyphae, turns reddish brown in $\mathrm{KOH}$ after 10-15 minutes, later fades out to grayish color. Subhymenium pseudoparenchymatous. Stipe cuticle hyphal, context hyphae parallel, thin-walled 11.4-40 $\mu \mathrm{m}$ broad. Clamp connections present in stipe context hyphae.

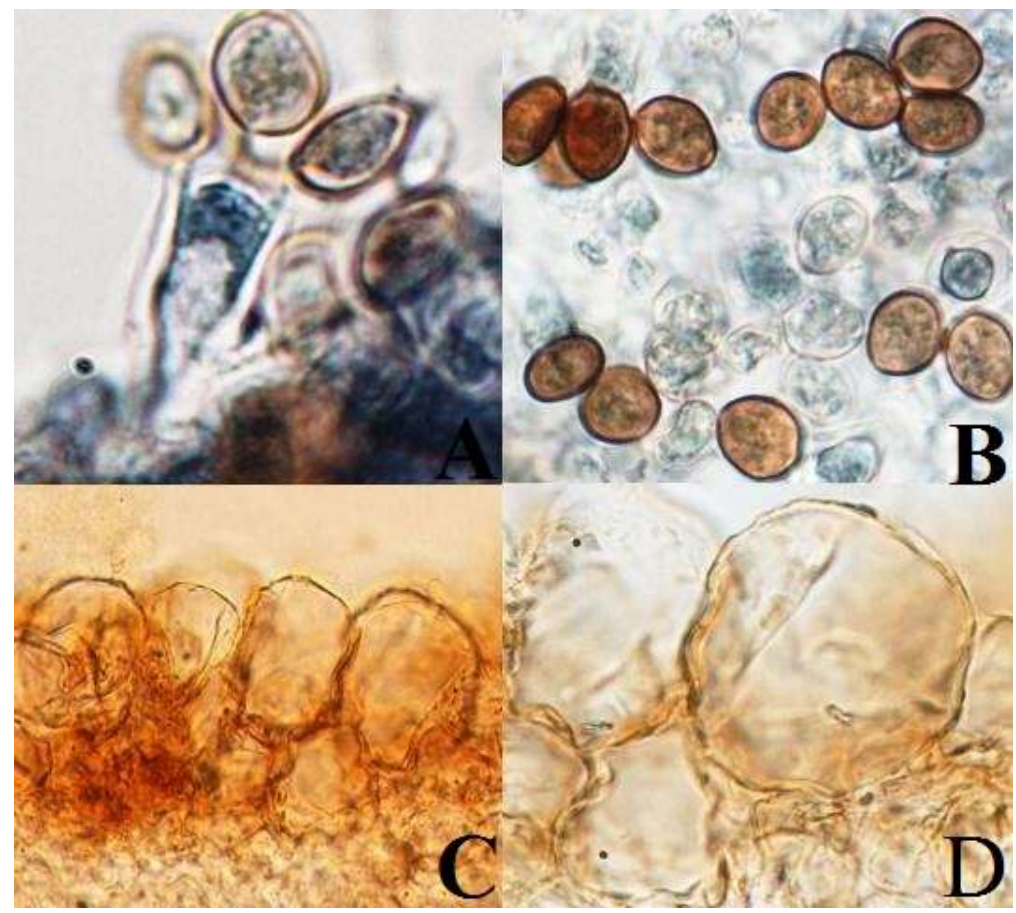

Fig. 5 - Psathyrella sphaerocystis. A Basidia. B Basidiospores. C Pileus cuticle. D Velar sphaerocyst. 


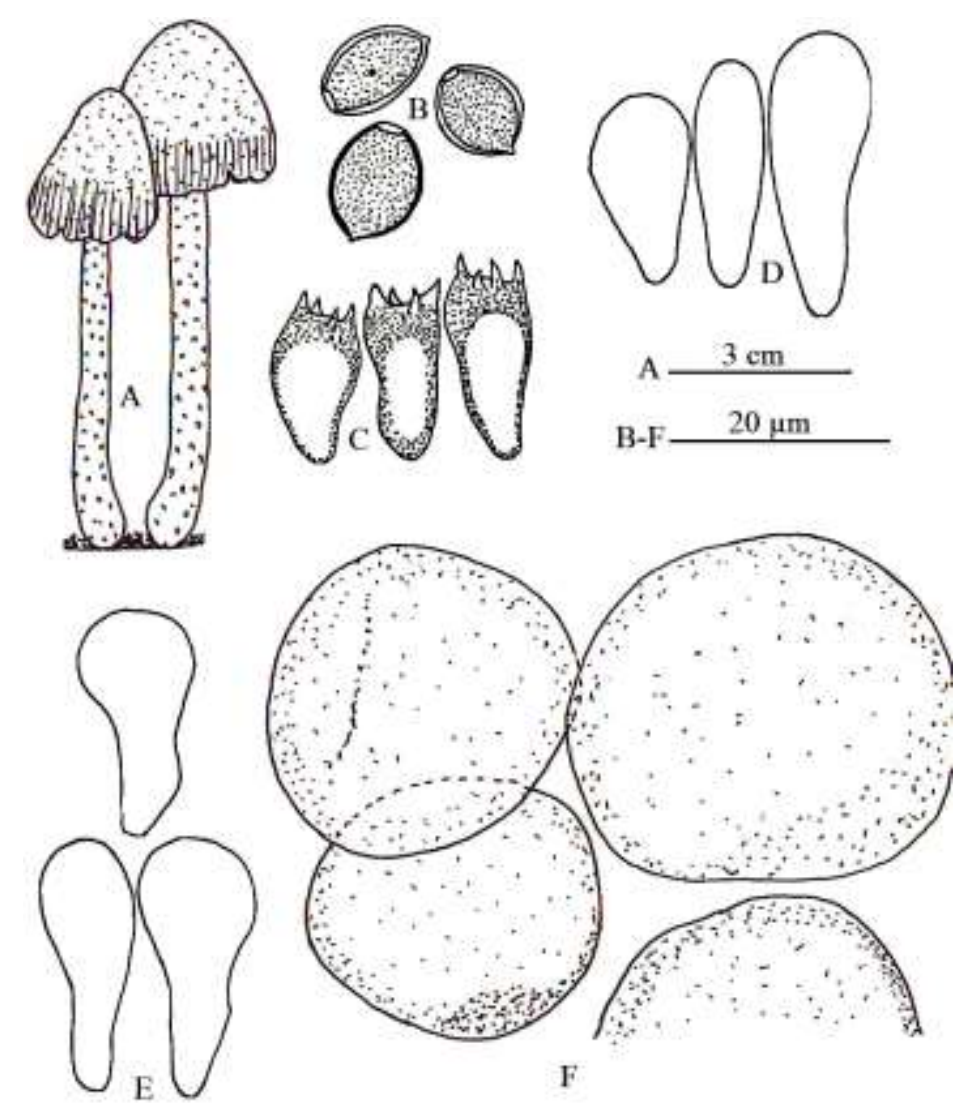

Fig. 6 - Psathyrella sphaerocystis. A Carpophores. B Basidiospores. C Basidia. D Cheilocystidia. E Pleurocystidia. F Veil sphaerocysts.

Material examined - India, Punjab, Sangrur, Balamgarh, alt. $231 \mathrm{~m}$, growing in caespitose cluster on mixed cattle dung heap, 30 July 2009, Amandeep Kaur, PUN 4075.

Discussion - The presently examined collection closely resembles with the taxonomic description of $P$. sphaerocystis as given by Smith (1972) except the spore size which measure from 7-10 (11) $\times 5-7(7.7) \mu \mathrm{m}$ in the presently examined collection as compared to 7-9 $\times 4.5-5.5 \mu \mathrm{m}$ as reported by Smith (1972). This species belongs to subgenus Cystopsathyra Singer because of its veil characters. Despite slight difference in spore size, it has been placed in P. sphaerocystis as all other features are in agreement with the details of the species described by Smith (1972), Kits van Waveren (1985) and Larssona and Örstadius (2008). The closely related species $P$. fimiseda differs from it in having slightly larger cystidia and absence of clamps. Orton (1964) and Smith (1972) reported the species growing on horse dung. Present collection has been made from mixed cattle dung heap. It is a new fungus record for India.

Psathyrella flocculosa (Earle) A.H. Smith in Mem. N. Y. Bot. Gdn. 24: 181, $1972 . \quad$ Figs. 7 - 8 Basionym - Gymnochilus flocculosus Earle in Inf. An. Estac. Centr. Agron. 1: 238, 1906. Synonyms - Hypholoma flocculosum (Earle) Morgan in Jour. Mycol. 14: 65, 1908. Drosophila flocculosa (Earle) Murrill in Mycologia 10: 64, 1918.

Carpophores $2.2-3.2 \mathrm{~cm}$ in height. Pileus $1.6-2.4 \mathrm{~cm}$ broad, $1.4-2.0 \mathrm{~cm}$ high, conicocampanulate; surface moist, grayish brown $\left(6 \mathrm{E}_{3}\right)$ with brown $\left(6 \mathrm{E}_{7}\right)$ apex, hygrophanous, fading to pale buff; pileal veil arranged in fascicles, appressed floccose, white, removable; margin irregular, splitting at maturity, striate, with occasional appendiculate veil; cuticle fully peeling; flesh thin, fragile, white, becoming dull brown on bruising; taste mild, odor disagreeable. Lamellae adnexed, equal, crowded, narrow, white when young, grayish brown at maturity, fragile; gill edges smooth. Stipe 2.0-3.1 cm long, 0.4-0.6 cm broad, obclavate, tapering upwards, hollow, surface white, fibrillose, shiny, fragile; annulus absent. 


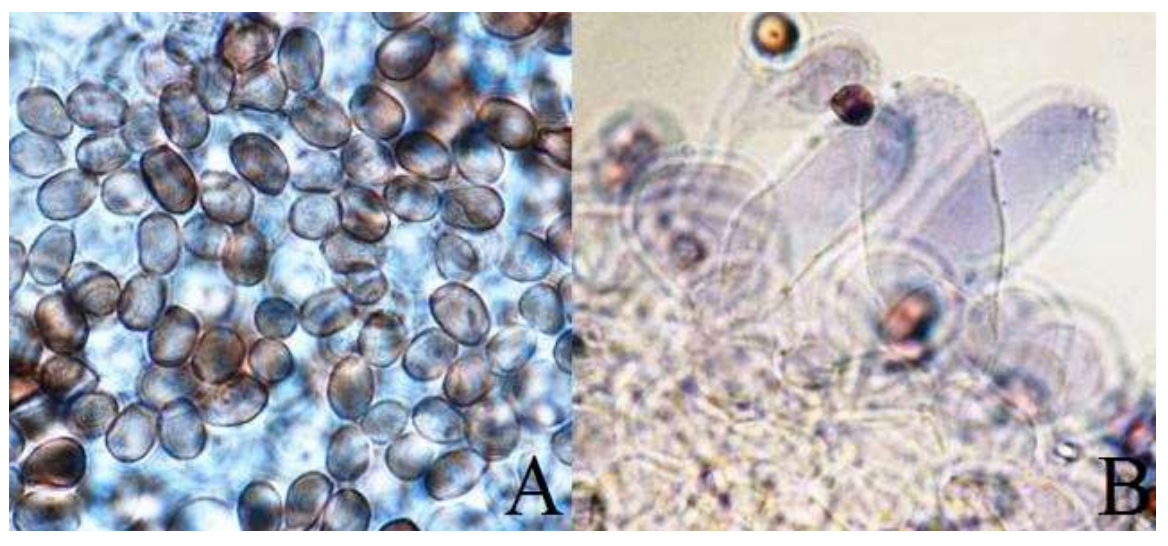

Fig. 7 - Psathyrella flocculosa. A Basidiospores. B cheilocystidia.

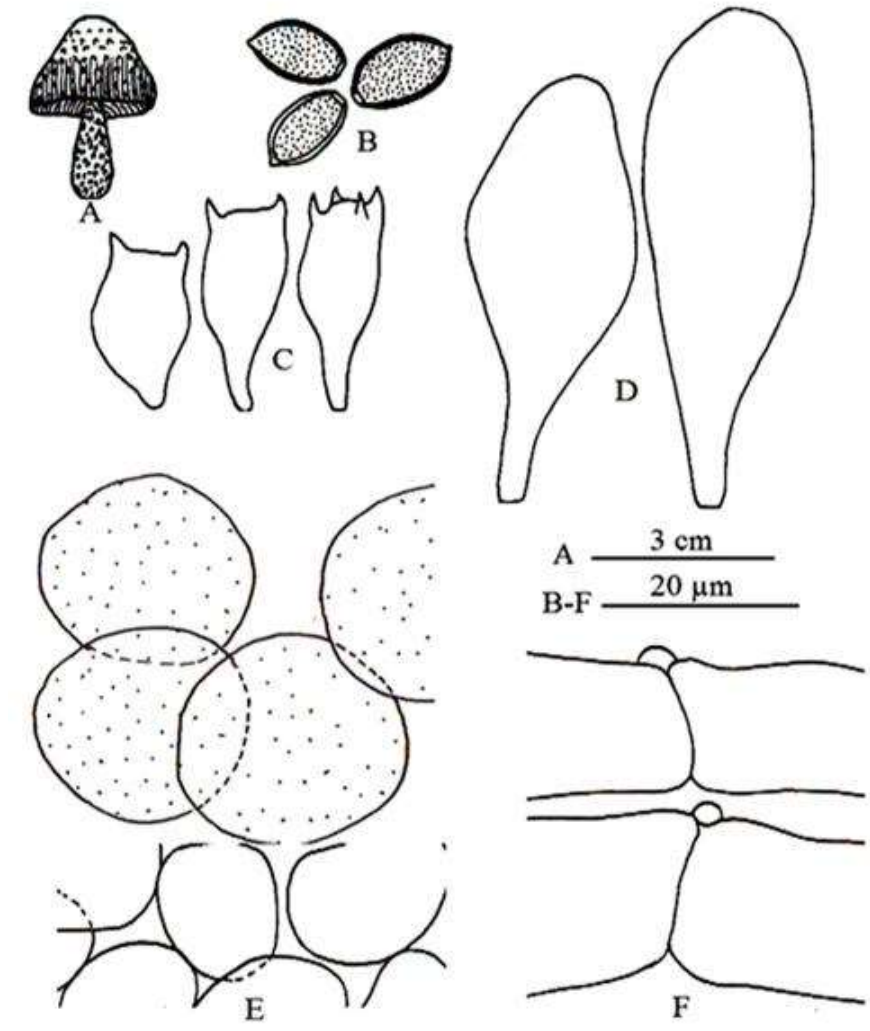

Fig. 8 - Psathyrella flocculosa. A Carpophore. B Basidiospores. C Basidia. D Cheilocystidia. E Pileal elements. F Clamp connections in stipe context hyphae.

Basidiospores $8.5-11 \times 4.7-6.8 \mu \mathrm{m}(\mathrm{Q}=1.7)$, ovoid to ellipsoidal, with a truncate germ pore, thick-walled, smooth, rusty brown in water, grayish brown to dark brown in $\mathrm{KOH}$, reddish brown in Melzer's reagent, bleach in concentrated $\mathrm{H}_{2} \mathrm{SO}_{4}$; apiculus $1.7 \mu \mathrm{m}$ long. Basidia 15.2-23.7 $\times 6.7-9.3 \mu \mathrm{m}$, clavate to clavate pedicellate, $2-$ and 4-spored, thin-walled, hyaline; sterigmata $2.5-$ $3.4 \mu \mathrm{m}$ long. Gill edges sterile. Cheilocystidia 47-60 × 17-22 $\mu \mathrm{m}$, vesiculose, clavate to ventricose, with round apex, thin-walled, hyaline. Pleurocystidia absent. Pileus cuticle 2-3 layered deep cellular epithelium with subglobose veil remnants; cells $6.8-17 \times 6.8-14 \mu \mathrm{m}$, subglobose, thinwalled, smooth, hyaline; pileus context homoiomerous, made up of interwoven thin-walled hyaline 3.4-10 $\mu \mathrm{m}$ broad hyphae, grayish to hyaline in $\mathrm{KOH}$. Hymenophoral trama regular, composed of thin-walled 2.5-7.6 $\mu \mathrm{m}$ broad hyphae. Subhymenium pseudoparenchymatous. Stipe cuticle hyphal, context hyphae parallel, thin-walled, hyaline 6.7-20 $\mu \mathrm{m}$ broad. Clamp connections present in pileus and stipe context hyphae. 
Material examined - India, Punjab, Sangrur, Naushehra, alt. 231 m, growing gregariously on mixed cattle dung heap, 07 July 2007, Amandeep Kaur, PUN 4074.

Discussion - In the presently examined collection the morphological and microscopic characters are similar to those given for P. flocculosa by Smith (1972). The species belongs to subgenus and section Pannucia (Karsten) Smith and subsection Flocculosae Smith. Brown colored pileus fading to pale buff and well developed floccose veil both at the pileus and stipe surfaces are unique features of this species. Psathyrella hymenocephala can be distinguished by red-brown to chocolate-colored pileus and spores appearing minutely echinulate when mounted in Melzer's reagent. Smith (1972) reported P. flocculosa growing gregariously on damp ground from Cuba. Presently this species was documented growing gregariously from cattle dung in the beginning of the monsoon season in July. It is a new fungus record from India.

\section{Acknowledgement}

Authors acknowledge the grant-in-aid under SAP-III programme by University Grants Commission to the Department of Botany, Punjabi University, Patiala, Punjab of which Mycology and Plant Pathology is one of the thrust areas.

\section{References}

Amandeep K, NS Atri, Munruchi K. 2013 - A new species of Psathyrella (Psathyrellaceae, Agaricales) collected on dung from Punjab, India. Journal on New Biological Reports 2(3), 275-280.

Atri NS, Kaur A, Kour H. 2005 - Wild mushrooms-collection and identification. In: Frontiers in Mushroom Biotechnology (eds RD Rai, RC Upadhyay, SR Sharma). NRCM Solan, Himachal Pradesh, India, pp 9-26.

Atri NS, Saini SS. 2000 - Collection and study of Agarics- An introduction. Indian Journal of Mushrooms 18(1\&2), 1-5.

Kaur H, Munruchi K, Atri NS, Kaur A. 2013 - The Genus Psathyrella (Fr.) Quél. from India: New Records. Journal on New Biological Reports 2(1), 55-63.

Kaur M, Kaur B, Kaur H, Atri NS. 2011 - The Genus Psathyrella (Fr.) Quél from India. Journal of Mycology and Plant Pathology 41, 584-588.

Kirk PF, Cannon PF, Minter DW, Stalpers JA. 2008 - Ainsworth and Bisby's Dictionary of Fungi, 10th ed, CABI Bioscience, CAB International, UK.

Kits van Waveren E 1985 - The Dutch, French, and British species of Psathyrella. Persoonia 2 (Suppl.), 1-300.

Kornerup A, Wanscher JH. 1978 - Methuen Handbook of Colour, 3rd ed, Eyre Methuen, London.

Kuo M 2011a - Psathyrella candolleana. Retrieved from the MushroomExpert.Com Web site: http://www.mushroomexpert.com/psathyrella_candolleana.html

Kuo M 2011b - Psathyrella incerta. Retrieved from the MushroomExpert.Com Web site: http://www.mushroomexpert.com/psathyrella_incerta.html

Larssona E, Örstadius L. 2008 - Fourteen coprophilous species of Psathyrella identified in the Nordic countries using morphology and nuclear rDNA sequence data. Mycological Research 112, 1165-1185.

Mohanan C 2011 - Macrofungi of Kerala. KFRI Handbook No. 27, Kerala Forest Research Institute, Peechi, Kerala, India.

Natarajan K, Kumaresan V, Narayanan K. 2005 - A checklist of Indian Agarics and Boletes (19842002). Kavaka 33, 61-128.

Orton PD 1964 - Notes on British agarics- II. Notes from the Royal Botanical Garden Edinburgh 26, 43-65.

Pegler DN 1977 - A Preliminary Agaric flora of East Africa. Kew Bulletin Additional Series 6, London. pp 615.

Pegler DN 1986 - Agaric flora of Sri Lanka. Kew Bulletin Additional Series 12, London. pp 514. 
Pushpa H, Purushothama KB. 2013 - Psathyrella candolleana var. indica (Agaricales) a new variety from Karnataka state, India. International Journal of Biological Research 1 (1), 1-7.

Saini SS, Atri NS. 1993 - North Indian Agaricales-IV. Indian Journal of Mycology and Plant Pathology 23, 250-254.

Saini SS, Atri NS. 1995 - Mushroom flora of Punjab. In: Advances in Horticulture Vol 13Mushrooms (eds KL Chadha, SR Sharma). Malhotra Publishing House, New Delhi, India, pp 375-386.

Sarwal BM, Rawla GS. 1983. Taxonomic studies on Indian Agarics - III. Bibliotheca Mycologica 91, 541-548.

Singer R 1986 - The Agaricales in Modern Taxonomy, 4th ed, Sven Koeiltz Scientific Books, Germany. pp 981.

Smith AH 1949 - Mushrooms in their Natural Habitats, Hafner Press, New York. pp 626.

Smith AH 1972 - The North American Species of Psathyrella. Memoris of the New York Botanical Garden 24, New York, pp 633. 